\title{
'Plenty of room' revisited
}

\author{
Who was Richard Feynman and what did he actually say about nanotechnology?
}

It is an unwritten rule on Nature Nanotechnology that Richard Feynman's famous 1959 lecture 'There's plenty of room at the bottom' should not be referred to at the start of articles unless absolutely necessary. It is not that we have anything against Feynman or this lecture - quite the opposite. Rather, our unwritten rule is intended to encourage variety in the introductions of articles, which is why we also discourage references to Moore's law in opening sentences. However, we are making an exception for this issue because it contains a number of articles ${ }^{1}$ that mark the 50th anniversary of Feynman's lecture, which he delivered to a meeting of the American Physical Society at the California Institute of Technology on 29 December 1959 (ref. 2).

Back in 1959, 41-year-old Feynman was one of the leading theoretical physicists in the world, and his work on quantum electrodynamics in the early 1940s would earn him a share of the Nobel Prize for Physics in 1965. However, this was a few years before his famous Feynman Lectures on Physics ${ }^{3}$ had made him a household name among physics undergraduates, and a few decades before he would become famous well beyond the physics community thanks to his 1985 autobiography, 'Surely You're Joking, Mr Feynman!'4, and his work on the presidential commission that investigated the Challenger space shuttle disaster of 1986 . Whoever invited Feynman to speak at the American Physical Society meeting deserves credit for their foresight.

\section{It is possible to read the lecture as a manifesto for physicists to take control of both the physical and biological sciences.}

Back in 1959 it was only six years since Crick and Watson had determined the double-helix structure of DNA, the laser and Silicon Valley were still taking shape, Feynman's Caltech rival and colleague Murray Gell-Mann had yet to propose the quark model of particle physics, and scanning probe

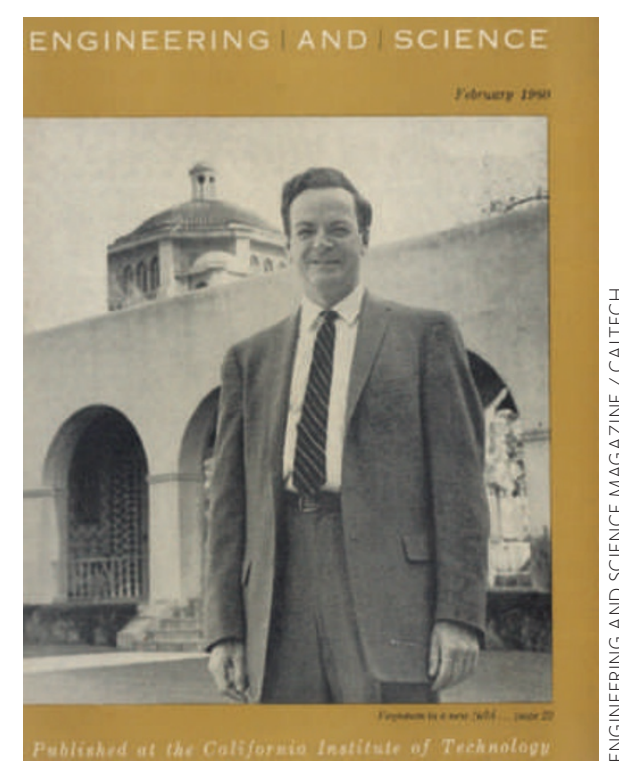

points out on page 785, 'Plenty of room' was “a very minor incident in Feynman's brilliant career", and he got some things right and some things wrong.

Chris Toumey has probably done more than anyone to analyse the true impact of 'Plenty of room' on the development of nanotechnology by revealing, among other things, that it was only cited seven times in the first two decades after it was first published in the Caltech magazine Engineering and Science in 1960 (ref. 5). However, as nanotechnology emerged as a major area of research following the invention of the scanning tunnelling microscope in 1981, and culminating in the famous IBM paper of 1991, "it needed an authoritative account of its origin," writes Toumey on page 783 . "Pointing back to Feynman's lecture would give nanotechnology an early date of birth and it would connect nanotechnology to the genius, the personality and the eloquence of Richard P. Feynman."

Feynman's 1959 lecture ventured far beyond physics.

microscopes and carbon nanotubes were still decades away. (See page 803 for a review of the state-of-the-art in atomic force microscopy).

Although Feynman was speaking at a physics meeting, and the subtitle for his lecture was 'An invitation to enter a new field of physics', he did not confine himself to his own back yard. Indeed, it is possible to read the lecture as a manifesto for physicists to take control of both the physical and biological sciences. And it is little wonder that chemists in particular have bridled at some of Feynman's comments about chemical synthesis: "A chemist comes to us and says, 'Look, I want a molecule that has the atoms arranged this and so; make me that molecule.' The chemist does a mysterious thing when he wants to make a molecule. He sees that it has got that ring, so he mixes this and that, and he shakes it, and he fiddles around."

But to dwell on these aspects of the lecture would be an injustice to the intellectual firepower that Feynman brought to a wide range of subjects within physics and beyond (and would also overlook the elements of the clown and the showman that were very much part of Feynman's character). As Richard Jones
Feynman devoted a significant part of 'Plenty of room' to electron microscopy, stressing the breakthroughs that would be possible in many areas of science if it were possible to "just look at the thing!" As Michael Segal reports on page 786 , the latest generation of electron microscopes are capable of resolutions of $0.5 \AA$. However, the damage caused to the samples being imaged by the electron beam has been a major problem, especially in biology. This opened the way for X-ray crystallography to have a larger impact, although the introduction of aberration correctors has allowed researchers to improve resolution while using lessdamaging lower-energy beams.

Re-reading 'Plenty of room' with its bizarre mix of ångströms and inches, with Feynman's verve and back-of-the-envelope calculations, with its insights and red herrings, with the benefit of hindsight, is always rewarding. If you have never read it, you really should.

\footnotetext{
References

1. http://www.nature.com/nnano/focus/plenty-of-room/index.html

2. Feynman, R. P. Engineering and Science 22-36 (February 1960).

3. Feynman, R. P., Leighton, R. B. \& Sands, M. Feynman Lectures on Physics (Vols 1-3) (Addison Wesley, 1963).

4. Feynman, R. P. 'Surely You're Joking, Mr Feynman!' Adventures of a Curious Character (W. W. Norton, 1985).

5. Toumey, C. Engineering and Science 16-23 (June 2005).
} 